\title{
Identifying Culs-De-Sac Courtyard Neighbourhoods in Shah Alam
}

\author{
Anniz Fazli Ibrahim Bajunid, Mohamed Yusoff Abbas, Abdul Hadi Nawawi \\ Centre for Environment-Behaviour Studies, \\ Faculty of Architecture, Planning and Surveying, \\ Universiti Teknologi MARA, 40450 Shah Alam, Malaysia \\ toanniz@gmail.com, cebsuitm@gmail.com, hadinawawi@yahoo.com
}

\begin{abstract}
Culs-de-sac in Shah Alam, have begun to take centre stage, especially in the high-end neighbourhood developments. Typically, these neighbourhoods can be easily identified. However, in contrast to developed nations, the local municipality has yet to begin identifying neighbourhood typologies. This paper endeavors to elucidate a sampling or identification process procedures of the cul-de-sac neighbourhood. The cul-de-sac was identified by observing intersection connectivity, link-node ratios, as well as street segment analysis; an assimilation of techniques used in recent western methodologies. Scaled macro to micro map analysis aligned sequentially in sieves, allow for identification of specific cul-de-sac syntax; one in particular is the cul-de-sac courtyards.
\end{abstract}

Keywords: Cul-de-sac courtyards; neighbourhood identification; cul-de-sac syntax; way of life; Tessellation Planning

eISSN 2514-751X @ 2018. The Authors. Published for AMER ABRA cE-Bs by e-International Publishing House, Ltd., UK. This is an open-access article under the CC BY-NC-ND license (http://creativecommons.org/licenses/bync-nd/4.0/). Peer-review under responsibility of AMER (Association of Malaysian Environment-Behaviour Researchers), ABRA (Association of Behavioural Researchers on Asians) and $c E-B s$ (Centre for EnvironmentBehaviour Studies), Faculty of Architecture, Planning \& Surveying, Universiti Teknologi MARA, Malaysia.

DOI: https://doi.org/10.21834/aje-bs.v3i9.295 


\subsection{Introduction}

Identifying culs-de-sac seem rather elementary in the context of town and neighbourhood planning. This process may seem even counterintuitive to planners and architects, particularly in developed nations. Outside the United States, United Kingdom and Australia, however, little is known on the processes of cul-de-sac neighbourhood identification. In Malaysia particularly, where available quantifiable physical data of town planning is modest and limited, this process remains elusive to many professionals and researchers in the built environment.

Literatures on the cul-de-sac include numerous western planners and researchers. But on the local scene, there are several indications of deliberations of the local Authorities and researchers on the matter of the cul-de-sac (indirect implications as well), produced mainly in reports. These reports, relevant to this paper, include the Department of Statistics Malaysia (2011a, b); Federal Department of Town and Country Planning (2011); Selangor Department of Town and Country Planning. (2010); Shah Alam City Council (2010a, b.); Unit Khas NKRA Bandar Selamat (2010a, b). Other publications include peripheral inferences to the cul-de-sac, such as the studies of Ghazali \& Bajunid (2011). One such ongoing, specific investigation on the cul-de-sac within the local realm, is that of Bajunid, et. al. (2012a, c, d).

This paper strives to emphasize on the methodologies of the identification processes of the cul-de-sac, within the scope of the Malaysian, Shah Alam City Council (MBSA) district.

\subsection{Literature Sourcing}

\subsection{Refinement, Extensiveness and Multi-Disciplinary Hits of Searches}

A series of Boolean logic of a string of keywords in the search for literature in the digital construct was useful in the search for identification of cul-de-sac in a broad-spectrum, in order to have an impression of available documents available in the ever expanding academic, worldwide web.

In a series of literature sourcing of the cul-de-sac, from broad interpretations to relevancy to the Malaysian context, Bajunid, et. al. (2012a, b, c) adapted a series of systematic reviews. This meticulous process was undertaken to ensure the extensiveness of the documentation search across disciplines worldwide, in the digital domain, within the search time span of January to December 2011.

Figure 1 visually extracts a snapshot of journal domains and current authors and researchers engaged in a research within the peripheral and direct studies of the cul-de-sac and its neighbourhood.

There are over 15 domains to date, which exemplify the multidisciplinary of the cul-desac (Bajunid, et. al., 2012a). The domains, however, transect rather ambiguously in a few key areas, as illustrated in Figure 2. Whilst it is acceptable that the domains are constantly maturing and dynamically evolving, it would also be permissible to assume that a certain pattern has begun to take form. This can additionally be acknowledged with themes and issues revolving around the macro- and micro- neighbourhood specifics. (Bajunid, et. al., 2012c). 


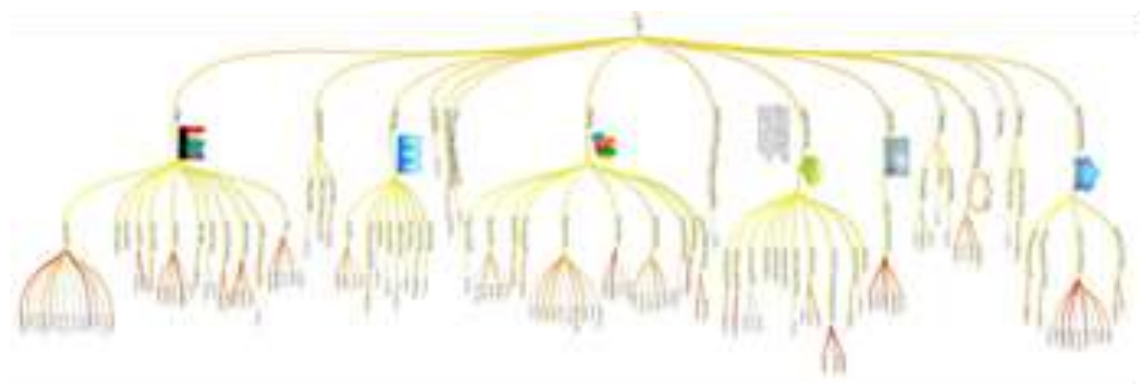

${ }^{*} B a s e d$ on the Boolean logic of specific keywords. The inclusion criteria for the search were 74 databases and 23 academic domains (Bajunid, et. al. 2012a). To note also that the illustration only represents current mapping at the time this paper was written.

Figure 1: Journal categorization mind-mapping (shown are only subsamples) (Source: Author, 2011)

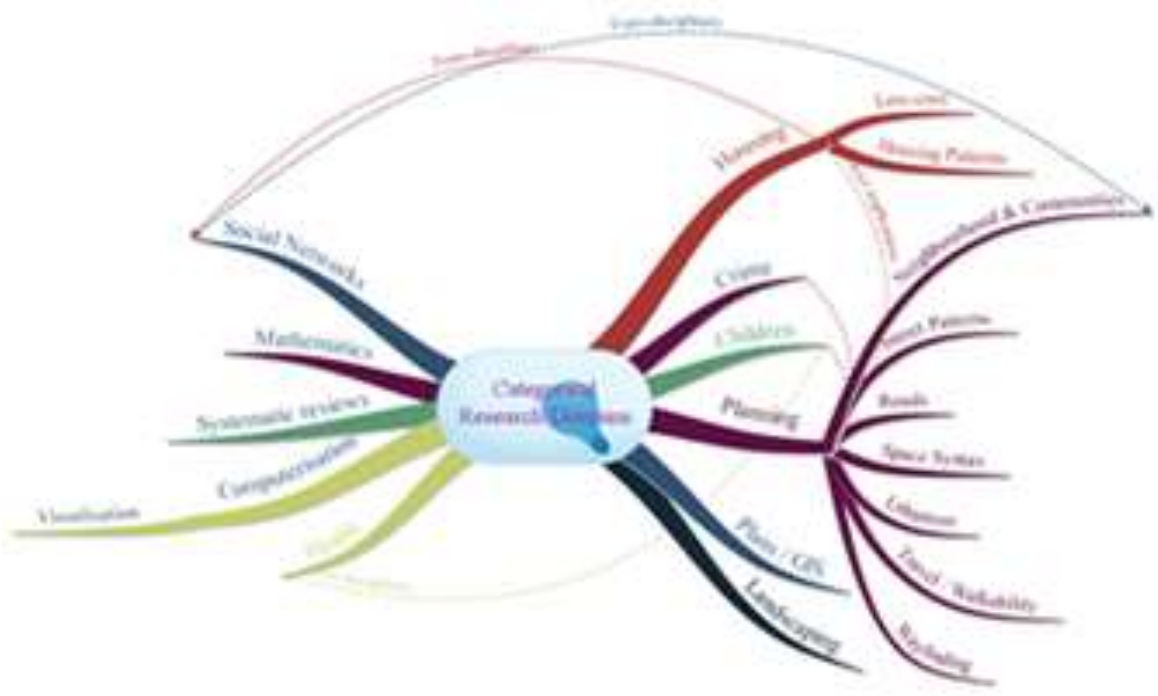

*The illustration depicts the published materials of the cul-de-sac and the environment-behaviour categories within major issues of the macro and micro neighbourhood. (Current trans-disciplinary mapping at the time this paper was written.)

Figure 2: Mapping the Trans-disciplinary Domains of the Culs-de-sac

(Source: Author, 2011) 


\subsection{Discourses On Classification And Identification Of The Cul-De-Sac}

\subsection{Expanding Archives}

A pooled result of over 104 relevant materials was obtained and shall be postulated in a brief summary, alongside three (3) ongoing academic publication milestones of a $\mathrm{PhD}$ research on the cul-de-sac. With an extension of the discussed literature sourcing above, a table illustrating the screening processes and relevancy to the cul-de-sac has been illustrated in Table 1.

\section{Table 1}

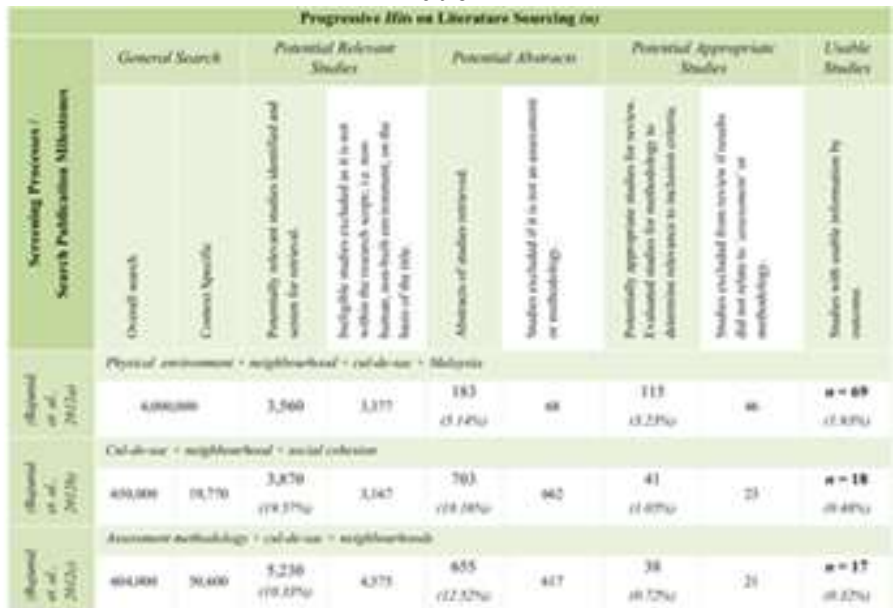

*The table represents the screening processes for relevancy being reviewed for identification processes of the culde-sac. The table represents a glimpse of the multiple searches conducted continuously within a time frame of about a year (2011) within the maximum capacity of the largest University in Malaysia. The percentages (\%) are only a mere indication of available, relevant data extracted from each stage of the filtering processes. For full

tabulation and listing of keyword strings and searches, the individual papers are available online.

(Source: Adaptation from a QUOROM 1999 (Quality of Reporting of Meta-analyses) / CONSORT 2010 (Consolidated Standards of Reporting Trials) flowchart. (Moher, et al., 2010).

\subsection{Relevant Precedents}

Indications reflected in Table 1 denote a certain recognisable pattern. The quantifiable literature found in relevance to the culs-de-sac micro-neighbourhood in context of the identification processes remains vague when compared to other typical street type typology. This is justifiable as common design planning practices are usually linear in arrangements as to accommodate vehicular patterns whereas culs-de-sac are planning specifics to a certain typology of housing arrangements. This adheres to another point for further investigations within the disparity of knowledge of street patterns, and even further within the context of environment-behaviour. To an extent, it seems the contribution of the local context 
to be almost inconsequential. Then again, a few recent local published papers argue the need for broader research (Ghazali \& Bajunid, 2011).

The international findings do present a series of possibilities in the application within the local setting. As explained and deliberated by Bajunid, et. al. (2012c), two (2) current researchers dictated sampling processes and identification of cul-de-sac. It may seem uncommon within the disciplines of road transportation, street networks or civil engineering, but the trans-disciplinary application towards the built and social environment (environmentbehaviour) remains unique. Hou, et. al. (2010), explained the processes endured by the research team in ascertaining measures of street networks within a larger sample area.

While the application may only be relevant in terms of the link-node ratio, it provides this paper scientific grounding in identifying culs-de-sac in the larger setting.

Johnson \& Bowers's (2010) findings identified the cul-de-sac subtle impermeability, as a deterrent to burglary risk. They emphasised that this was enhanced in a sinuous type of a cul-de-sac. In their methodology, in classifying street segments, they were exceptionally careful in ensuring that the culs-de-sac within their Ordnance Survey area were not misidentified. This brought them back to the conventional and labour-intensive of manual identification of every cul-de-sac. It is this critical juncture that this paper surmises that the effectiveness and validity of current identification and classifying processes still lay within manual identification, especially within the available resources of developing Malaysia.

Three (3) technical meetings were conducted with the Shah Alam City Council (MBSA) Planning Department (A. Jumisry, Personal Interview, 8, 20, 25 October 2011). The meetings were to ascertain available documents and statistics pertaining to culs-de-sac in the MBSA jurisdiction. It was explained with dismay that even though MBSA was regarded as one of the advance municipalities in the Klang Valley, no such information of street segments, neighbourhood typologies or cul-de-sac exists. However, a number of peripheral municipal reports on housing and the neighbourhood as a whole, particularly on Crime Prevention through Environmental Design (CPTED) and Gated and Guarded Communities is available (Shah Alam City Council, 2010a, b.; Unit Khas NKRA Bandar Selamat, 2010a, b.) which has identified and outlined the design guideline of the cul-de-sac as a design measure to encourage natural surveillance.

Three (3) meetings were also conducted with the Selangor and Federal Department of Town and Country Planning (JPBD) as well as the Department of Statistics Malaysia. The meetings were similarly unable to establish any tangible data of the micro neighbourhood, yet alone the cul-de-sac. This poses yet another challenge, but one that received support for the continued study and the pursuit by the various departments in an effort to assist in research and development towards mutual benefits in modernising the current systems (A. Jamal, Personal Interview, 20 April 2012). Yet, peripheral documentation (Department of Statistics Malaysia, 2011a, b), with indications of the cul-de-sac as the preferred design in neighbourhood planning (Federal Department of Town and Country Planning, 2011; Selangor Department of Town and Country Planning, 2010) were also available.

The focus of the remainder of this paper, within the design terminology of the cul-de-sac itself, shall be that of the conventional design of a courtyard that is naturally formed within the cul-de-sac, with only one point of entry and exit, or typically referred to local designers 
and planners as cul-de-sac courtyards. This direct approach to contextual processes along with multiple site observations for triangulation purposes shall also delimit the scope and findings.

\subsection{Identification Processes Of The Cul-De-Sac (Refer Table 2)}

\subsection{Acquisition and Sieving of Technical Data and Maps}

The first initiation of the identification of the cul-de-sac began with the availability of different types and scale of maps. These maps were made available by numerous sources, namely Peta Cadangan Guna Tanah (Map of Proposed Land Uses) MBSA in Shah Alam City Council (2010a); Peta Panduan Jalan Bandaraya (Road Map Guide) in Shah Alam City Council (2010b); Google Earth; Google Maps, as well as systematic on-site assessments.

In order to ensure the best identification of culs-de-sac within the street networks of MBSA, sieves were proportionately layered according to predetermined scales. The scales we determined by visual legibility of each map, in search for a cul-de-sac. A constant (datum), was selected, in this case, the culs-de-sac of Seksyen 18 (18/5A, 14A), Figure 3. This selection was due to its obvious physical, geometric, oval appearance and its scale for immediate legibility when scouring the different scaled maps. A pilot visit to the cul-de-sac determined the actual size and corresponding dimensions. Google Earth and Google Maps were used as well in determining the actual extent of the constant.

The reference point of Seksyen 18 made possible the continuous consistency in regulating street sizes and the extent of each neighbourhood unit and the cul-de-sac courtyard. This further ensures the reliability of researchers in the identification processes.

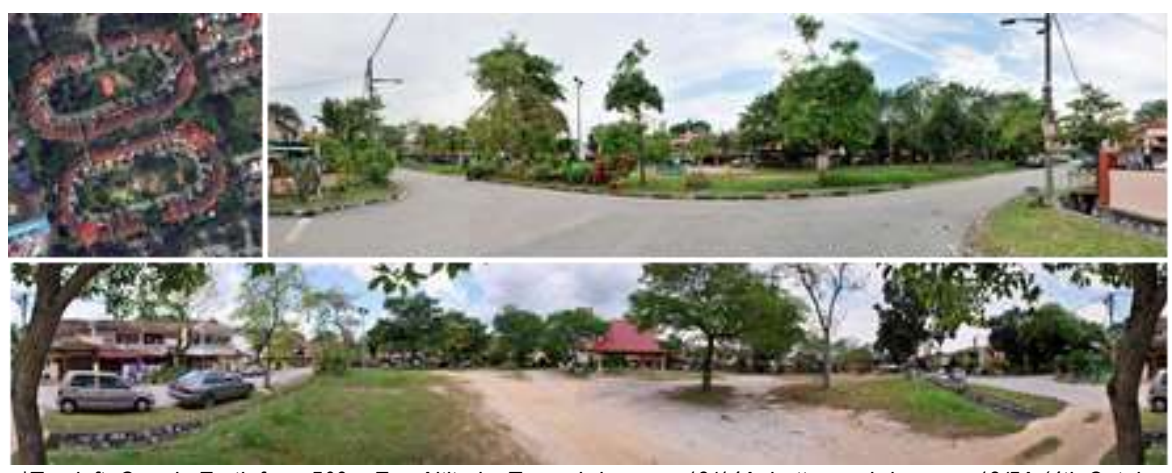

*Top left: Google Earth from 509m Eye Altitude. Top cul-de-sac - 18/14A, bottom cul-de-sac - 18/5A (4th October 2011). Top Right: Neighbourhood Panorama 1, street approach into the cul-de-sac 18/14A. Bottom: Neighbourhood Panorama 2, cul-de-sac courtyard 18/5A.

Figure 3: Technical Visual Analysis of Seksyen 18 (18/5A, 14A) Cul-de-sac (Source: Author, 28 September 2011) 


\subsection{Characterisation and Coding}

Subsequent to the establishment of the datum, the researcher then proceeded with grid by grid detection according to each map's relevant scale. This process mimics in reliability and consistency of the processes of Johnson \& Bowers's (2010). Street networks were soon after determined to correspond to the cul-de-sac courtyard criteria of one entry and exit point. Colour coding was also used in differentiating the degree and intensity of the cul-de-sac courtyard inclusion criteria (Figure 4). Successively, digital re-identification refines the process to reduce inaccuracies in the identification and misidentification. Finally, all manual and digitally identified cul-de-sac courtyards were personally visited and observed to ensure its absolute validity.

\subsection{Macro to Micro Identification of Cul-De-Sac Courtyards}

The identification processes of the cul-de-sac courtyards could be seen in Table 2. The table illustrates in detail the entire processes involved in the identification of a cul-de-sac courtyard. The process is generic and shall allow for different derivation of cul-de-sac identification or street pattern identification. However, as new neighbourhoods develop and master plans change, the reliability of maps is limited within just a short span of a few years. Timeconsuming and costly, it is finally advised that a final site visit and observation be the final, valid triangulation. This is assuming that the municipality has yet to document their street networks and neighbourhoods.
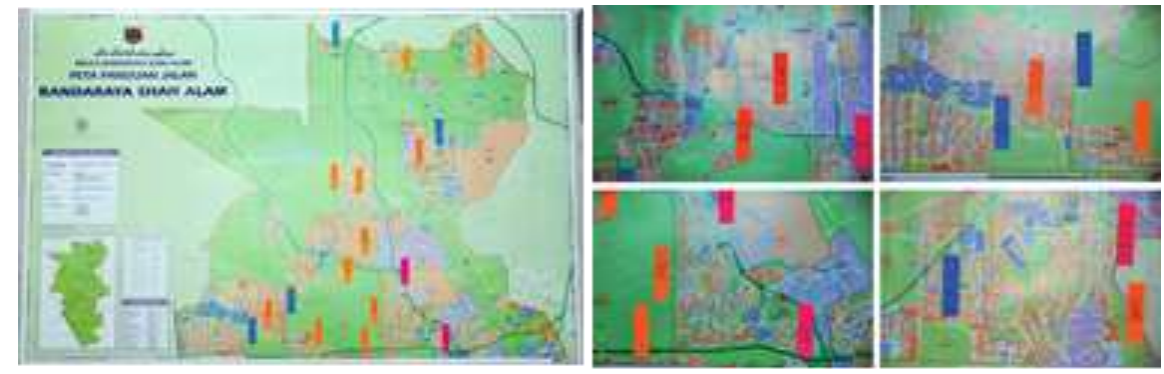

*Left: Street Map of MBSA (Northern Region). Grid by grid manual identification, colour coding and sieving of street patterns. Right: Detailed Street Map of MBSA. (Map source: Jabatan Perancang, Tingkat 9, Majlis Bandaraya Shah Alam, Wisma MBSA, 40000 Shah Alam [JUPEM.BP.24.04.01.jld 74(24)]).

Figure 4: Macro and Micro Identification of Cul-de-sac Courtyards

(Source: Author, 15 September 2011) 


\section{Table 2}

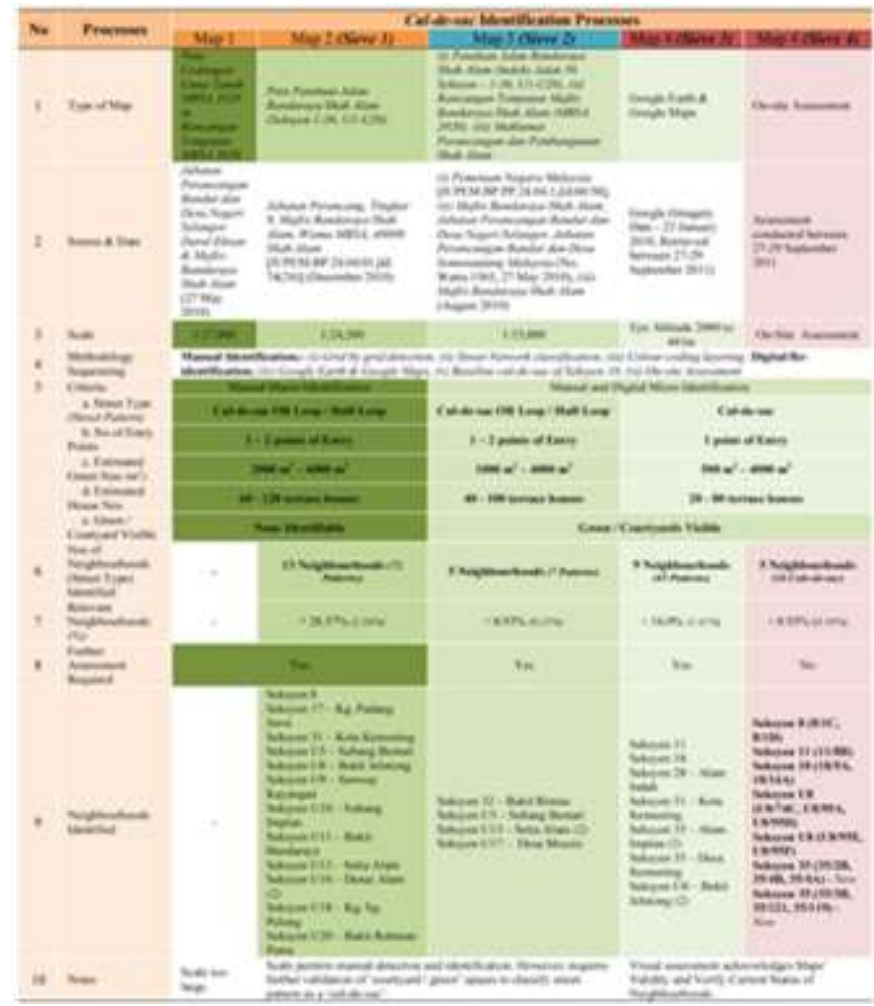

*Explanatory Notes:- Process No:- (7) MBSA Total Jurisdiction - $290.3 \mathrm{~km}^{2}$ (71,734.42 acres) with 56 Seksyen. Percentage reflects estimated neighbourhoods to the total number of Seksyen. A more detailed identification, grid by grid, could be obtained through the Author. Culs-de-sac percentages are based on Panduan Jalan Bandaraya Shah Alam (Indeks Jalan 56 Seksyen - 1-36, U1-U20) [Pemetaan Negara Malaysia, JUPEM.BP.PP.24.04.1.jld.60/58] consisting of estimated \pm 3180 Streets.

(Source: Author, 2011)

\subsection{Conclusion}

The processes described earlier were explicit in the identification of specific cul-de-sac courtyards in the Shah Alam City Council (MBSA) district. It has to be noted that other municipalities may not have sufficient data such as that of Shah Alam which requires large pool of resources. It is also the inherent characteristic of cul-de-sac that it is only available to cities and townships of a suburban nature and of a medium density. These criteria shall be the delimitations and selection criteria of potential townships as future case studies.

Understanding the cul-de-sac syntaxes may pose a conundrum if planning of neighbourhoods is only dictated by linear and or loop layouts. There are already many derivatives of the cul-de-sac such as the fused grid (Canada) (M. Ghazali, Personal 
Communication, March 23, 2009) or even Tessellation Planning (Ghazali \& Bajunid, 2011). Further possibilities and opportunities lie within the development of cul-de-sac syntaxes of our micro neighbourhoods which requires further research.

\section{Acknowledgement}

The Author is appreciative of the expertise of the supervisory committee and to industry collaborators for their practical and applied evaluations. A remark of indebtedness is also owed to the Ministry of Higher Education, for its grant award and Universiti Teknologi MARA (UiTM) for the perpetual research encouragement. The Author also wishes to acknowledge the complete and extended version of this paper that can be sourced from Procedia - Social and Behavioural Sciences.

\section{References}

Bajunid, A. F. I., Abbas, M. Y., \& Nawawi, A. H. (2012a). Tessellation Planning: 'Creating the Other Space'. Procedia - Social and Behavioral Sciences, 36(0), 493-501. doi: 10.1016/j.sbspro.2012.03.054

Bajunid, A. F. I., Abbas, M. Y., \& Nawawi, A. H. (2012b). The Malaysian Cul-de-sac Neighbourhoods: Does It Foster Social Cohesion of Communities? Procedia - Social and Behavioral Sciences, 35(0), 652-658. doi: 10.1016/j.sbspro.2012.02.133.

Bajunid, A. F. I., Abbas, M. Y., \& Nawawi, A. H. (2012c). Assessing Cul-de-sac Neighbourhoods: A Methodological Prelude. Procedia - Social and Behavioral Sciences(0). doi: https://doi.org/10.1016/j.sbspro.2013.06.553

Department of Statistics Malaysia (2011a). Population and Housing Census of Malaysia 2010: Population Distribution by Local Authority Areas and Mukims. (ISBN 97898390 44591). Putrajaya, Malaysia: Department of Statistics Malaysia.

Department of Statistics Malaysia (2011b). Statistik Utama Selangor 2010 (Main Statistics of Selangor 2010). (ISSN 2231-8496). Selangor: Jabatan Perangkaan Malaysia (Department of Statistics Malaysia).

Federal Department of Town and Country Planning (2011). Garis Panduan Perancangan Perumahan (Draf Kedua 17 Jun 2011). (ISBN 978-983-41729-6-1). Malaysia: Federal Department of Town and Country Planning, Ministry of Housing and Local Government Malaysia.

Ghazali, M., \& Bajunid, A. F. I. (2011). Tessellation Planning and the Small Neighbourhood as an Appropriate Scale for Social Amenities and Engineering Infrastructure to Meet Urban Needs. Paper presented at the 13th International Conference on Humane Habitat (ICHH), Mumbai, India.

Hou, N., Popkin, B. M., Jacobs Jr, D. R., Song, Y., Guilkey, D., Lewis, C. E., et al. (2010) Longitudinal Associations Between Neighborhood-Level Street Network with Walking, Bicycling, and Jogging: The CARDIA Study. Health \& Place, 16(6), 1206-1215.

Johnson, S., \& Bowers, K. (2010). Permeability and Burglary Risk: Are Cul-de-Sacs Safer? Journal of Quantitative Criminology, 26(1), 89-111. doi: 10.1007/s10940-009-9084-8

Moher, D., Hopewell, S., Schulz, K. F., Montori, V., Gøtzsche, P. C., Devereaux, P. J., . . Altman, D. G. (2010). CONSORT 2010 Explanation and Elaboration: updated guidelines for reporting parallel group randomised trials. British Medical Journal (BMJ), 340(c869), 1-28. doi: 10.1136/bmj.c869 
Selangor Department of Town and Country Planning. (2010). Garis Panduan dan Piawaian Perancangan Negeri Selangor (Edisi Kedua). Malaysia: Department of Town and Country Planning, Selangor.

Shah Alam City Council (2010a). Rancangan Tempatan Majlis Bandaraya Shah Alam 2020. Selangor: Majlis Bandaraya Shah Alam

Shah Alam City Council (2010b). Panduan Jalan Bandaraya Shah Alam. (JUPEM.BP.PP.24.04.1.JLD.60/58). Selangor: Department of Survey and Mapping Malaysia.

Unit Khas NKRA Bandar Selamat (2010a). Crime Prevention Through Environmental Design (CPTED) Implementation Guide. (ISBN 978-967-5456-17-6). Kuala Lumpur: Federal Department of Town and Country Planning, Ministry of Housing and Local Government Malaysia.

Unit Khas NKRA Bandar Selamat (2010b). Safe City 2010. (ISBN 978-967-5456-12-1). Kuala Lumpur: Federal Department of Town and Country Planning, Ministry of Housing and Local Government Malaysia. 